\title{
Functioning of the Colicin A Lysis Protein is Affected by Triton X-100, Divalent Cations and EDTA
}

\author{
By DANIÈLE CAVARD,* S. PETER HOWARD† AND \\ CLAUDE LAZDUNSK I \\ Centre de Biochimie et de Biologie Moléculaire du CNRS, 31 Chemin Joseph Aiguier, BP 71, \\ 13402 Marseille Cedex 9, France
}

(Received 10 October 1988; revised 25 January 1989; accepted 1 March 1989)

The colicin A lysis protein, Cal, is synthesized at the same time as colicin A by Escherichia coli harbouring plasmid pColA after induction by mitomycin $\mathrm{C}$. Its function in the induced bacteria involves the release of colicin A, quasi-lysis, the death of the producing cells and the activation of the outer membrane phospholipase $\mathrm{A}$. We have found that these various functions are affected differently by treatment of the induced cells with Triton $\mathrm{X}-100$, divalent cations or EDTA. Triton X-100 and EDTA caused increased quasi-lysis and a higher level of mortality of the producing cells, but while Triton X-100 enhanced the release of colicin A, EDTA reduced it. Divalent cations protected the cells against both killing and quasi-lysis without greatly affecting colicin release. The effects of these agents were similar for both wild-type and phospholipase A mutants and depended only on the presence of a functional cal gene.

\section{INTRODUCTION}

It has been demonstrated that the release of colicin A from producing Escherichia coli cells is entirely dependent on the synthesis of the colicin A lysis protein (Baty et al., 1987b). This protein, called Cal, is a small lipoprotein of 33 amino acids that is induced under SOS control at the same time as colicin A. It is synthesized in precursor form and undergoes modification and processing reactions similar to those of the major lipoprotein of the outer membrane. A small amount of $\mathrm{Cal}$ is released to the medium together with large amounts of colicin A (Cavard et al., 1985, 1987).

The Cal protein is highly homologous to lysis proteins encoded by other colicin or cloacin plasmids (De Graaf \& Oudega, 1986; Pugsley, 1988) with the exception of that one encoded by pColE9-J (James et al., 1987). The mode of action of these lysis proteins is unknown. They promote the release of colicins or cloacin by a lethal mechanism that involves a so-called 'quasilysis' of the producing cells and a necessary activation of the phospholipase A of the outer membrane at the time of colicin release (Pugsley \& Schwartz, 1984; Luirink et al., 1986; Cavard et al., 1987). Pugsley \& Schwartz $(1983,1984)$ have reported that Triton X-100 promotes colicin E2 release from induced cells carrying a functional lysis gene, even if the cells are devoid of phospholipase A. The detergent thus appears to bypass the requirement for phospholipase A activation. On the other hand, the divalent cations $\mathrm{Mg}^{2+}$ and $\mathrm{Ca}^{2+}$ have been shown to inhibit the quasi-lysis of induced cells provoked by the lysis proteins of colicins E1 and E2 and of cloacin DF13 (Altieri et al., 1986; Pugsley \& Schwartz, 1984; Luirink et al., 1986, 1987).

$\dagger$ Present address: Division of Basic Medical Sciences, Faculty of Medicine, Memorial University, St. John's, Newfoundland A1B 3V6, Canada.

Abbreviation: Cal, colicin A lysis protein. 
We report in this paper that Triton X-100 causes early release of both colicin A and its lysis protein, and that it is possible to selectively alter the functions of the Cal lysis protein, and furthermore, that $\mathrm{Cal}$ causes severe damage to induced cells even in the absence of phospholipase activation.

\section{METHODS}

Bacterial strains and plasmids. The strains Citrobacter freundii CA31 (pColA) and E. coli W3110 (pColA9) were used in most experiments. The plasmids pColA9, pJMM1, pX345, pAE11 and pAK31 have been described (Lloubès et al., 1986; Cavard et al., 1985, 1986, 1987).

Growth conditions. Strains were grown in LB medium or in M9 medium supplemented with thiamin $\left(1 \mu \mathrm{g} \mathrm{ml} \mathrm{m}^{-1}\right)$, glycerol $(0.4 \%, \mathrm{v} / \mathrm{v})$ and Casamino acids $(0.01 \%, \mathrm{w} / \mathrm{v})$. Plates of minimal or LB medium contained $1 \cdot 5 \%(\mathrm{w} / \mathrm{v})$ agar and $40 \mu \mathrm{g}$ ampicillin $\mathrm{ml}^{-1}$. Mitomycin $\mathrm{C}$ was used in cultures having an $\mathrm{OD}_{600}$ of 1 , using $300 \mathrm{ng} \mathrm{ml}^{-1}$ for E. coli strains and $100 \mathrm{ng} \mathrm{ml}^{-1}$ for Citrobacter CA31. All cultures were incubated at $37^{\circ} \mathrm{C}$ with good aeration. Optical density of the cultures was measured in a Kontron spectrophotometer.

Analysis of colicin A release and immunoblotting. Samples of a culture in LB medium treated with mitomycin C, or of a supernatant of the culture, were analysed by $12.5 \%(\mathrm{w} / \mathrm{v})$ SDS-PAGE (Cavard et al., 1985). Immunoblotting was performed as described by Baty et al. $(1987 b)$ with a rabbit anti-colicin A serum.

Labelling with radioactive methionine. Labelling conditions with $\left[{ }^{35} \mathrm{~S}\right] \mathrm{methionine}\left[10 \mu \mathrm{Ci} \mathrm{ml}{ }^{-1}, 1200 \mathrm{Ci} \mathrm{mmol}{ }^{-1}\right.$ $\left(44.4 \mathrm{TBq} \mathrm{mmol}{ }^{-1}\right)$ ] were as previously described (Cavard et al., 1987). Labelling was performed after 60 or $90 \mathrm{~min}$ of mitomycin $\mathrm{C}$ treatment for Citrobacter and $E$. coli strains, respectively. For pulse-chase experiments, $\left[{ }^{35}\right.$ S]methionine $\left[30 \mu \mathrm{Ci} \mathrm{ml}^{-1}\left(1 \cdot 11 \mathrm{MBq} \mathrm{ml}^{-1}\right)\right]$ was added and after $45 \mathrm{~s}$ unlabelled methionine was added to $100 \mu \mathrm{g} \mathrm{ml}^{-1}$. Samples of $10 \mu \mathrm{l}$ were taken at various times after the chase and mixed with $10 \mu \mathrm{lof}$ loading buffer and heated to $96^{\circ} \mathrm{C}$ before being analysed. Urea-SDS-polyacrylamide gels were electrophoresed and treated as described previously (Cavard et al., 1987).

Strain construction. An E. coli W3110 pldA strain was constructed by P1 transduction. First, a W3110 met $\mathrm{E}:: \mathrm{Tn} 10$ was constructed by $\mathrm{P} 1$ transduction from $E$. coli 403 met $\mathrm{E}:: \mathrm{Tn} 10$ and selection on tetracycline plates. This strain was then transduced with P1 grown on strain PC1602 pldA (a generous gift of Dr J. Tommassen, Institute of Molecular Biology and Medical Biotechnology, University of Utrecht, Utrecht, Holland). Transductants were selected on minimal medium plates and screened for the loss of tetracycline resistance. The pldA maker was tested as follows. Cells were transformed with pColA9, grown in LB medium and treated or not treated with mitomycin $\mathrm{C}$ for $4 \mathrm{~h}$, after which their phospholipids were extracted as described by Ames (1968) and analysed by thin-layer chromatography on silica gel plates. Clones in which the level of lysophosphatidylethanolamine was not increased by mitomycin $\mathrm{C}$ were considered as pldA and were called CBM.

Chemicals. Mitomycin $\mathrm{C}$ was purchased from Sigma. All other chemicals used were reagent grade.

\section{RESULTS}

\section{Effects of divalent cations, EDTA and Triton $X-100$ on Cal protein function}

In a culture of $E$. coli $\mathrm{W} 3110$ (pColA9), addition of mitomycin $\mathrm{C}$ induces the synthesis of both Cal and colicin A (Lloubès et al., 1986). In LB medium, the optical density of the culture increases during the first hour of induction and then decreases with time until a value lower than that at the time of mitomycin $\mathrm{C}$ addition is reached. This 'quasi-lysis' indicates a functioning lysis protein and is correlated with the release of colicin A (Cavard et al., 1987).

In the presence of Triton X-100 $(0 \cdot 1 \%)$ or of EDTA $(1 \mathrm{mM})$, the quasi-lysis of the induced cells was more significant than that of the control cells (Fig. 1a). In contrast, in the presence of $20 \mathrm{~mm}^{-\mathrm{MgSO}_{4}}$, no decline in $\mathrm{OD}_{600}$ was observed but the $\mathrm{OD}_{600}$ of the induced cells reached a plateau after $2 \mathrm{~h}$ of induction. Elimination of $\mathrm{Mg}^{2+}$ ions by the addition of EDTA provoked an immediate decrease of $40 \%$ in the $\mathrm{OD}_{600}$ of the culture (Fig. 1 c). The addition of $\mathrm{CaCl}_{2}$ had the same effect on quasi-lysis as that of $\mathrm{MgSO}_{4}$ (data not shown). [It should be noted that the growth of control (uninduced) cells was slower in the presence of EDTA but normal in the presence of Triton X-100 or $\mathrm{MgSO}_{4}$ at the concentrations used.]

We have found that quasi-lysis and colicin A release are greatly reduced in strain PC1602 pldA (Cavard et al., 1987). We then tested the effect of $\mathrm{Mg}^{2+}$ ions, EDTA or Triton X-100 addition on strain CBM(pColA9), a pldA mutant isogenic to W3110. Quasi-lysis was much reduced for pldA cells but was partially restored in the presence of Triton X-100 and was almost normal in the 



Fig. 1. Effect of Triton X-100, $\mathrm{Mg}^{2+}$ ions and EDTA on the quasi-lysis of colicin A producing cells. (a); A culture of $E$. coli W3110(pColA9) in LB medium was split into two parts, one of which was treated with mitomycin $\mathrm{C}(\mathrm{M}$, filled symbols) and the other untreated $(\mathrm{C}$, open symbols) at zero time. Each one was distributed into four flasks: in one, Triton X-100 was added to $0.1 \%$ concentration ( $\boldsymbol{\nabla}, \mathrm{MTx}$; or $\nabla, \mathrm{CTx}$ ), in the second, EDTA was added to $1 \mathrm{mM}(\boldsymbol{\Lambda}, \mathrm{ME} ;$ or $\triangle, \mathrm{CE})$, in the third, $\mathrm{MgSO}_{4}$ was added to $20 \mathrm{mM}(\square, \mathrm{MMg}$; or $\square, \mathrm{CMg})$, and in the fourth, nothing was added $(\boldsymbol{O}, \mathrm{M}$; or $\mathrm{O}, \mathrm{C})$. The $\mathrm{OD}_{600}$ of the cultures was measured at various times of induction. (b) The same experimental conditions were used as in (a) but with cells of $E$. coli $\mathrm{CBM}$ (pColA9). The $\mathrm{OD}_{600}$ of the control cultures in the presence of either Triton X-100 (CTx) or $\mathrm{MgSO}_{4}(\mathrm{CMg})$ was similar to that of the control cultures (C) and is not plotted on the figure. (c) After $3 \mathrm{~h}$ of induction, samples of control and mitomycin $\mathrm{C}$ cultures treated with $\mathrm{MgSO}_{4}$ were taken and added to various concentrations of EDTA immediately before their $\mathrm{OD}_{600}$ was measured. $\square$, Control cells of W3110(pColA9); $\square$, induced cells of W3110(pColA9); 0 , induced cells of CBM(pColA9). 

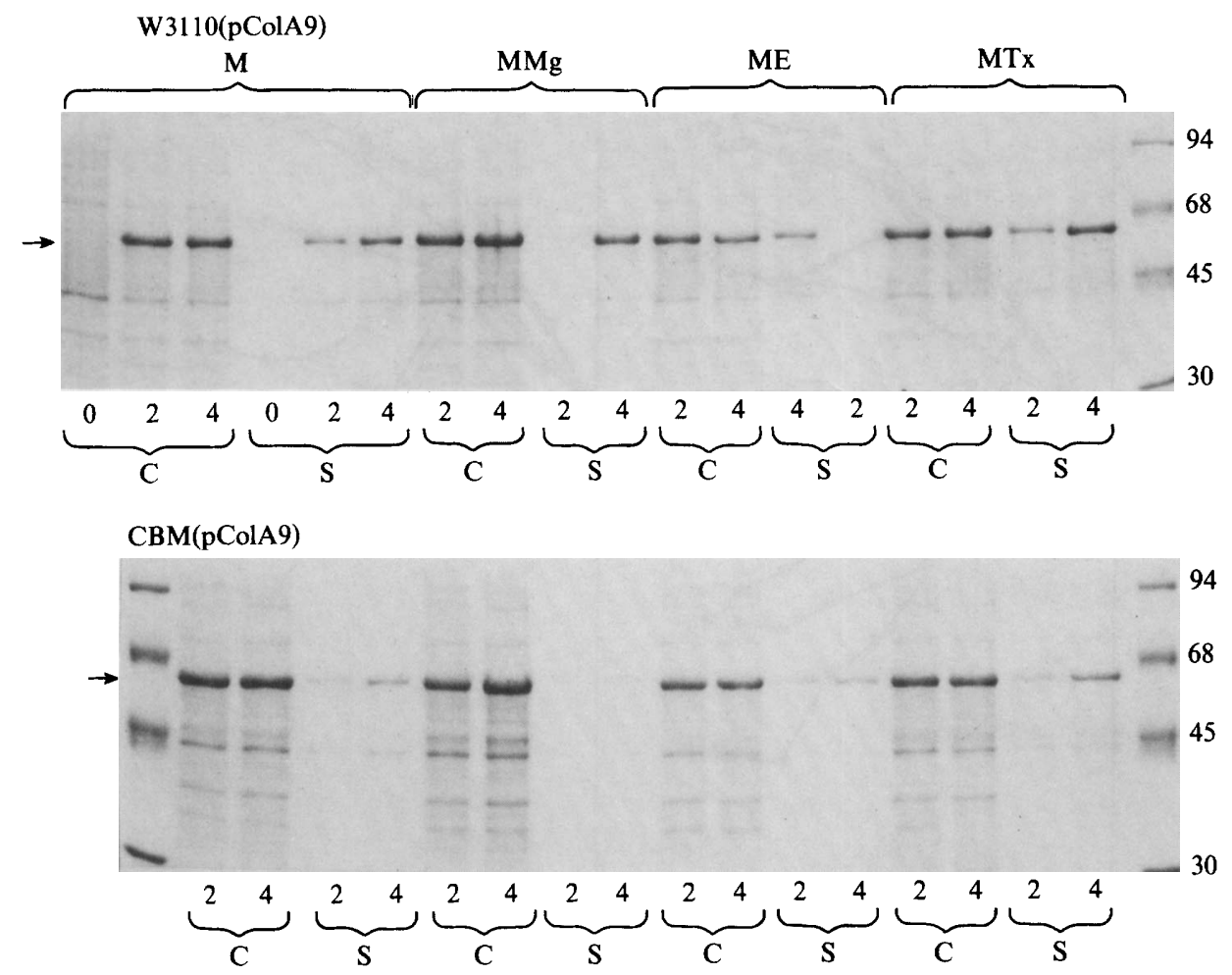

Fig. 2. Effect of Triton $\mathrm{X}-100, \mathrm{Mg}^{2+}$ ions and EDTA on colicin A release. In the same experiment as shown in Fig. 1, samples of cultures were taken after 2 and $4 \mathrm{~h}$ of induction and centrifuged. Equal amounts $(10 \mu \mathrm{l})$ of the cultures $(\mathrm{C})$ and supernatants $(\mathrm{S})$ were resuspended in loading buffer and analysed by SDS-PAGE. Part of the gel stained with Coomassie blue is presented. The position of colicin $\mathrm{A}$ is indicated by an arrow. Numbers on the right are the molecular masses of the standard proteins.

presence of EDTA (Fig. 1 b). In the presence of $\mathrm{MgSO}_{4}$, induced pldA cells behaved like control cells, with no decrease or early plateau in the $\mathrm{OD}_{600}$ of the culture.

The release of colicin A under these conditions was examined by analysis of the cultures and culture supernatants by SDS-PAGE (Fig. 2). Triton X-100 slightly increased the amount and the rate at which colicin A was released while both $\mathrm{Mg}^{2+}$ and EDTA decreased the rate and extent of release. Less colicin was synthesized in the presence of EDTA or Triton X-100 than in control cells. The early drop of $\mathrm{OD}_{600}$ provoked by EDTA or Triton X-100 thus seemed to be correlated with a decrease in the rate of synthesis of the colicin. In contrast, more colicin and more cell proteins were synthesized in presence of $\mathrm{Mg}^{2+}$ than in control cells, indicating that the continuous increase of $\mathrm{OD}_{600}$ was correlated to cell growth. In pldA cells, the release of colicin $\mathrm{A}$ was greatly reduced, as previously reported (Cavard et al., 1987). It was further decreased by EDTA or $\mathrm{Mg}^{2+}$ and slightly increased by Triton X-100 (Fig. 2).

The mortality of induced cells was checked in the presence of these various effectors by measuring the loss of colony-forming ability. As shown in Table 1, it was altered by the various treatments in the same manner as quasi-lysis. EDTA and Triton X-100 increased the killing significantly, while $\mathrm{MgSO}_{4}$ protected the cells, for both wild-type and pld $A$ cells. In addition, the number of CBM(pColA9) cells surviving after induction was 50 times higher than for the wildtype, suggesting that the activation of phospholipase $\mathrm{A}$ by $\mathrm{Cal}$ is an important part of the lethal process.

Fig. 3 shows the analysis on urea-SDS gels of pellets and supernatants of a culture in M9 medium of E. coli $\mathrm{W} 3110$ (pColA9) induced with mitomycin C in the presence of Triton X-100 or 


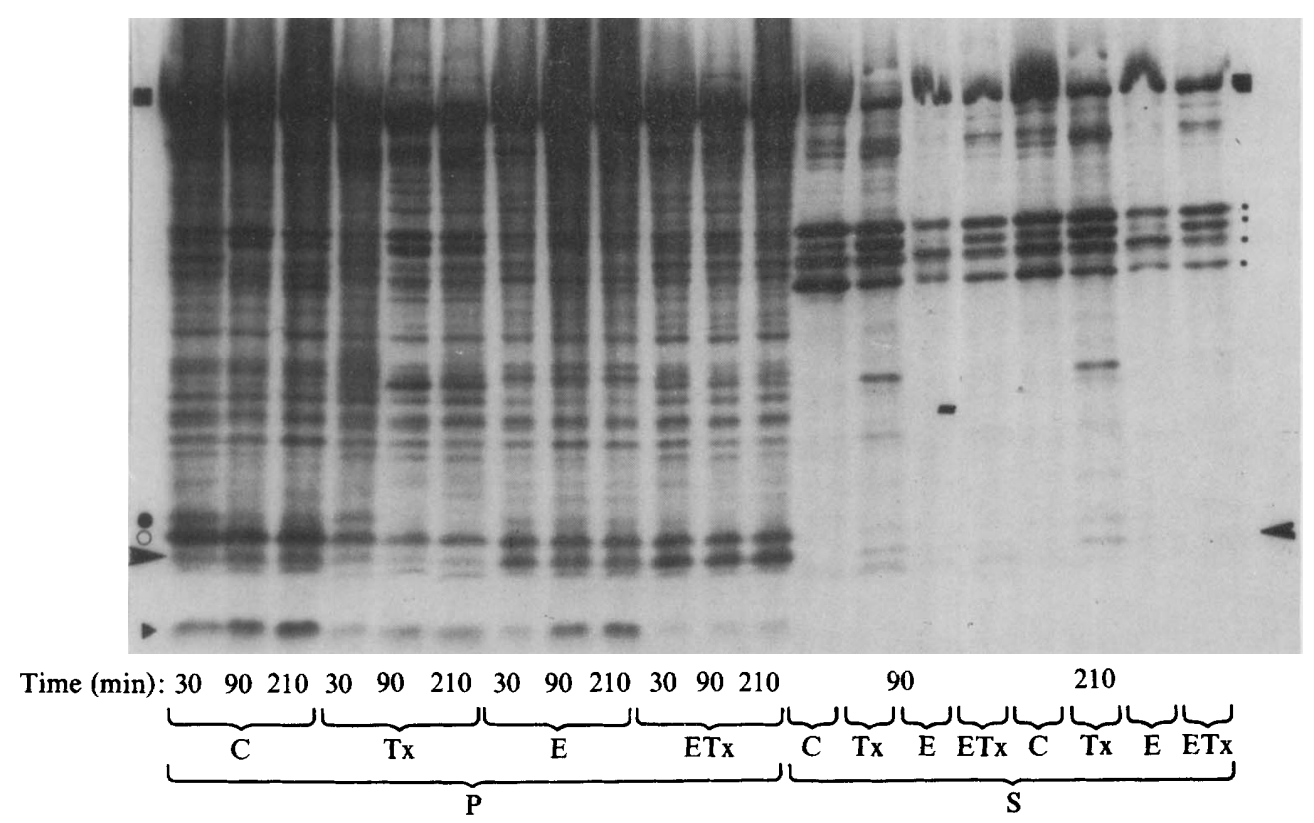

Fig. 3. Effect of Triton X-100 and EDTA on the release of colicin A and Cal. A culture of E. coli W3110(pColA9) in M9 medium was induced with mitomycin $C$ in the absence (C) or presence of $0 \cdot 1 \%$ Triton X-100 (Tx) or 2 mM-EDTA (E), or both Triton X-100 and EDTA (ETx). They were labelled for $5 \mathrm{~min}$ with $\left[{ }^{35} \mathrm{~S}\right] \mathrm{methionine}$ after $90 \mathrm{~min}$ of induction. At various times after labelling samples were collected and centrifuged for $1 \mathrm{~min}$ at $13000 \mathrm{~g}$. Pellets (P) were resuspended in loading buffer and heated before loaded on the gel. Samples $(10 \mu \mathrm{l})$ of supernatants were mixed with loading buffer, heated and loaded on the gel. The fluorogram of the urea-SDS gel is presented. Migrations of the colicin ( $\square$ ), colicin A fragments ( $\bullet$, modified precursor $\mathrm{Cal}(\boldsymbol{O})$, precursor $\mathrm{Cal}(\mathrm{O})$, mature $\mathrm{Cal}(\longrightarrow)$ and Cal signal peptide $(\rightarrow)$ are indicated.

Table 1. Effects of various treatments on colony-forming ability of induced cells

Treatment*

W3110(pColA9)

Non-induced

Non-induced + EDTA

Induced

Induced $+\mathrm{MgSO}_{4}$

Induced + EDTA

Induced + Triton X-100

CBM(pColA9)

Non-induced

Induced

Induced $+\mathrm{MgSO}_{4}$

Induced + EDTA

Induced + Triton X-100

$\overbrace{0}^{\text {C.f.u. } \mathrm{ml}^{-1}}$

$\begin{array}{lcr}1 \times 10^{9} & \text { ND } & 6.2 \times 10^{9} \\ 1 \times 10^{9} & \text { ND } & 2.5 \times 10^{9} \\ 1 \times 10^{9} & 1.7 \times 10^{7} & 1 \times 10^{6} \\ 1 \times 10^{9} & 2.2 \times 10^{8} & 5.5 \times 10^{7} \\ 1 \times 10^{9} & 1.3 \times 10^{6} & 3 \times 10^{4} \\ 1 \times 10^{9} & 1.3 \times 10^{7} & 8 \times 10^{5} \\ & & \\ 2 \times 10^{9} & \text { ND } & 7 \times 10^{9} \\ 2 \times 10^{9} & 2 \times 10^{8} & 1 \times 10^{8} \\ 2 \times 10^{9} & \text { ND } & 5.2 \times 10^{8} \\ 2 \times 10^{9} & \text { ND } & 6 \times 10^{4} \\ 2 \times 10^{9} & \text { ND } & 5 \times 10^{6}\end{array}$

ND, Not determined.

* Bacteria in LB medium were treated as reported in Fig. 1.

EDTA or both and labelled with ${ }^{[35}$ S $]$ methionine. As can be seen in the cell pellets $(\mathrm{P})$, differences in the accumulation of $\mathrm{Cal}$ were observed according to the effector added. In Triton X-100 treated cells, the level of mature Cal decreased after $30 \mathrm{~min}$ of labelling and then stayed constant with time. In contrast, in EDTA-treated cells, with or without added Triton X-100, 


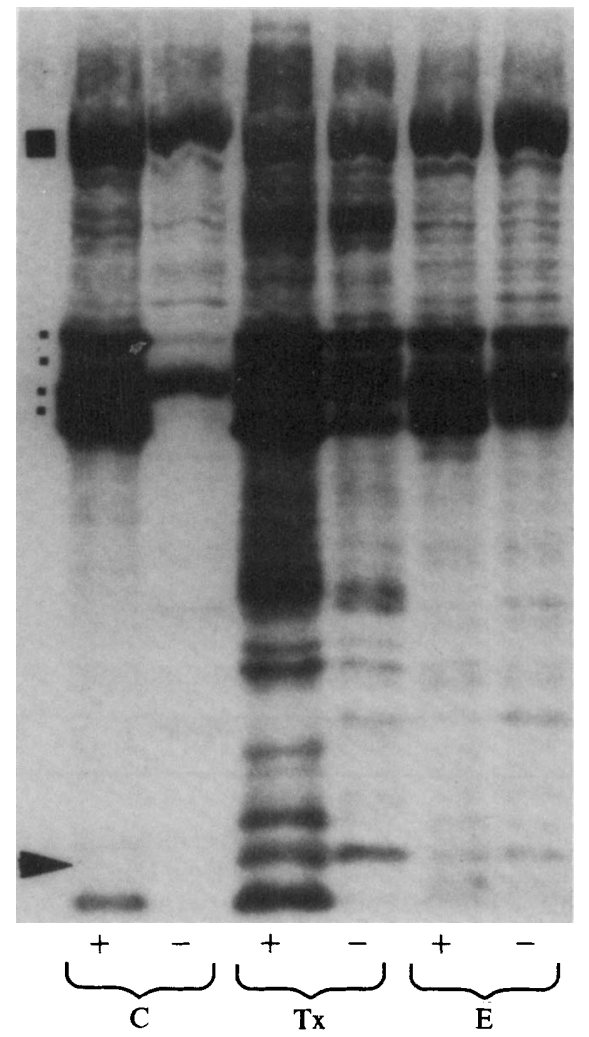

Fig. 4. Effect of Triton X-100 or EDTA on the release of colicin A and Cal in pld $A^{+}$or pldA strains. Cultures of $E$. coli W31 10(pColA9) ( + ) and of CBM pColA9 $(-)$ were induced, treated and labelled as indicated in Fig. 2. After $5 \mathrm{~h}$ of induction, samples were centrifuged and $10 \mu \mathrm{l}$ of the supernatants analysed on a urea-SDS gel. On the fluorogram, the migration of colicin A ( $\square$ ), fragments of colicin A $(\square)$ and mature Cal $(\rightarrow$ are indicated.

mature Cal was as stable as in control cells. In the supernatants (S), the release of both colicin A and mature $\mathrm{Cal}$ was observed. The release of $\mathrm{Cal}$ was significantly increased by treatment with Triton X-100, which explained the low level found in the cells. The release of Cal was unmodified by EDTA while the release of colicin A was inhibited. The addition of both Triton $\mathrm{X}-100$ and EDTA prevented the release of Cal caused by Triton X-100 alone, which was consistent with what was observed in the pellets. The addition of divalent cations had no effect on either Cal synthesis or release (data not shown). Colicin A in the supernatant was partly hydrolysed by proteases into fragments of about $30 \mathrm{kDa}$, indicated by dots in Fig. 3 and identified with anti-colicin $\mathrm{A}$ antibodies in an immunoblot (data not shown).

The addition of Triton X-100 or EDTA had the same effects on strain CBM(pColA9) as on strain W3110(pColA9). The supernatants of both pldA and pld $A^{+}$cells after $5 \mathrm{~h}$ of induction and labelling with [ ${ }^{35}$ S $]$ methionine are compared in Fig. 4. The release of colicin A and of Cal was greatly reduced in CBM(pColA9) compared to the wild-type strain but was greatly increased in the presence of Triton X-100. Under these conditions, the release of Cal approached the level observed for Triton X-100-treated wild-type cells. Treatment with EDTA also increased the release of $\mathrm{Cal}$ in $\mathrm{CBM}$ (pColA9) cells, although to a much lesser extent, as was observed for W3110(pColA9) cells. Again large amounts of colicin A fragments (shown by dots in Fig. 4) were observed; but these fragments were formed in larger amounts when CBM(pColA9) cells were treated with either Triton X-100 or EDTA than when untreated (Fig. 4, lane C). This 


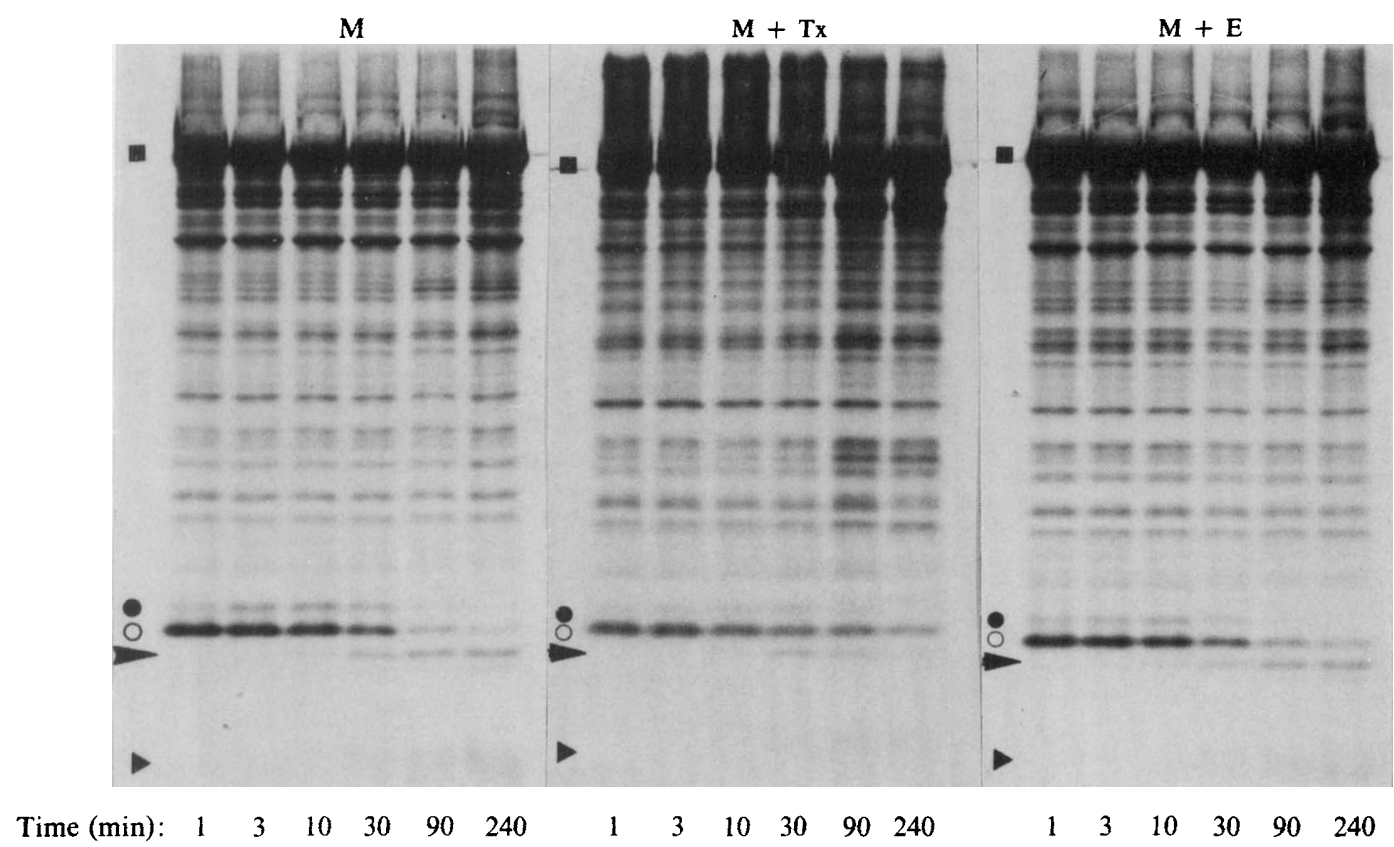

Fig. 5. Maturation and processing of Cal are unaffected by either Triton X-100 or EDTA. A culture of Citrobacter $\mathrm{CA} 31$ was induced with mitomycin $\mathrm{C}$ in the absence $(\mathrm{M})$ or presence of $0 \cdot 1 \%$ Triton X-100 $(M+T x)$ or of $2 \mathrm{mM}$-EDTA $(M+E)$. After $1 \mathrm{~h}$ of induction, cells were pulse-labelled for $40 \mathrm{~s}$ with $\left[{ }^{35} \mathrm{~S}\right]$ methionine $\left(50 \mu \mathrm{Ci} \mathrm{ml}{ }^{-1}\right)$. Samples $(10 \mu \mathrm{l})$ of the culture were taken at various times after the chase (indicated in the figure in min), mixed with $10 \mu$ l of loading buffer and loaded on a urea-SDS gel. A fluorogram of the gel is presented. Migrations of the various forms of $\mathrm{Cal}$ are indicated as in Fig. 3.

suggests that either some $E$. coli proteases are activated by detergent or that the susceptibility of colicin A to protease action is increased in the presence of either detergent or EDTA.

The effects described above were also observed with strains carrying plasmids encoding the cal gene but without an entire caa gene (Baty et al., 1987 b), both in E. coli or Citrobacter strains, and in either LB or M9 medium. The same effects were also obtained with cells carrying plasmid pColE1 (data not shown).

The modification and processing of Cal are not affected by either Triton X-100 or EDTA

The lipid modification and processing of Cal during colicin induction were examined in Citrobacter CA31 cells by pulse-labelling for $40 \mathrm{~s}$ with $\left[{ }^{35} \mathrm{~S}\right]$ methionine followed by a chase with unlabelled methionine. As seen in Fig. 5, addition of either Triton X-100 or EDTA at the time of induction did not affect the various steps of modification and processing of Cal. In each case, the Cal protein was synthesized under precursor form, pCal, which was slowly chased into a higher $M_{\mathrm{r}}$ modified precursor form $\left(\mathrm{pCal}^{\mathrm{m}}\right)$ by acylation. This form was then chased to the mature form plus its signal peptide, both of which accumulated in the cell with time. In each case, the entire process of Cal modification and processing was very slow, requiring at least $30 \mathrm{~min}$. The same kinetics were obtained in E. coli, as previously reported for wild-type cells (Cavard et al., 1987).

\section{Effective concentrations of Triton $X-100$, divalent cations and EDTA}

The effect of various concentrations of Triton $\mathrm{X}-100$ on the release of Cal from the induced cells to the culture supernatant is shown in Fig. 6. The extraction of Cal from the cells was maximum with the lowest concentration used $(0.04 \%)$ and did not increase with higher concentrations. It was also apparent that while increasing concentrations of Triton X-100 caused a progressive loss in the amount of the signal peptide in the cells, this material was not recovered in the supernatant. Increasing concentrations of Triton X-100 also caused increased 


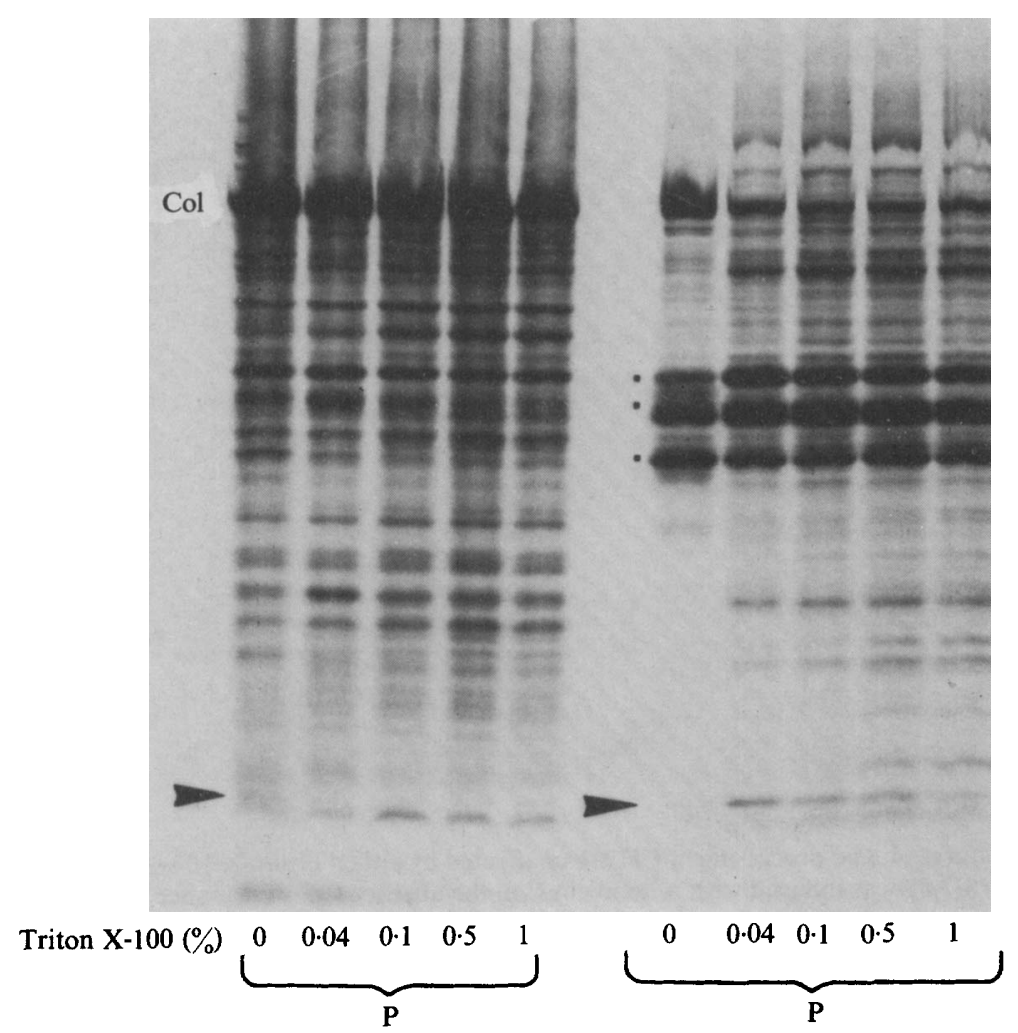

Fig. 6. Effect of various concentrations of Triton X-100 on Cal release. A culture of E. coli W3110 (pColA9) was treated with mitomycin $C$ in the absence or presence of $0,0.04,0.1$ or $1 \%$ Triton X-100. They were labelled with $\left[{ }^{35} \mathrm{~S}\right] \mathrm{methionine}$ as indicated in Fig. 3 . After $5 \mathrm{~h}$ of induction, samples were collected and centrifuged and pellets (P) and supernatants (S) were analysed on urea-SDS gel. On the fluorogram, the migrations of colicin A $(\mathrm{Col})$, fragments of colicin A $(\boldsymbol{\square})$ and mature Cal $(\rightarrow)$ are indicated.

break-down of colicin A released in the medium with formation of fragments around $30 \mathrm{kDa}$ (shown by dots in Fig. 6). This breakdown was not obtained with cells of Citrobacter CA31, indicating that it was due to $E$. coli protease(s).

The concentration range of $\mathrm{Mg}^{2+}$ ions effective in decreasing the quasi-lysis of induced cells was similar to that described for cloacin DF13 producing cells, between 5 and $20 \mathrm{mM}$ (Luirink $e t$ al., 1986). The optimal concentraion for W3110(pColA9) cells was $20 \mathrm{~mm}$. The effective concentration of EDTA was also tested. In M9 medium, which contains $1 \mathrm{mM}^{-\mathrm{Mg}^{2+} \text { and }}$ $0.1 \mathrm{mM}-\mathrm{Ca}^{+2}$, a concentration of $1.5 \mathrm{~mm}$-EDTA was effective in reducing the release of colicin A without causing the release of Cal. Further increases in the concentration of EDTA had no further effect, but inhibited growth.

\section{Effect of Triton $X-100$ on strains carrying plasmids with caa or cal mutations}

We have previously shown that strains carrying plasmids containing mutations in the cal gene (at the modification and cleavage site of the Cal precursor form) are unable to release colicin A (Cavard et al., 1987). In contrast, strains carrying a mutation in the caa gene are able to export the mutated colicin as long as the $\mathrm{cal}$ gene is functional and the mutant colicin is soluble (Baty $e t$ $a l ., 1987 a, b)$. In strain E. coli W3110(pAK31), the cal gene carries a mutation at the processing site such that the $\mathrm{Cal}$ protein is rapidly hydrolysed rather than being correctly modified. In strain W3110(pJMM1), transposon Tnl is inserted just upstream of the cal gene. In strain W31 10(pX345), the caa gene has been modified by mutagenesis such that the mutated colicin A 


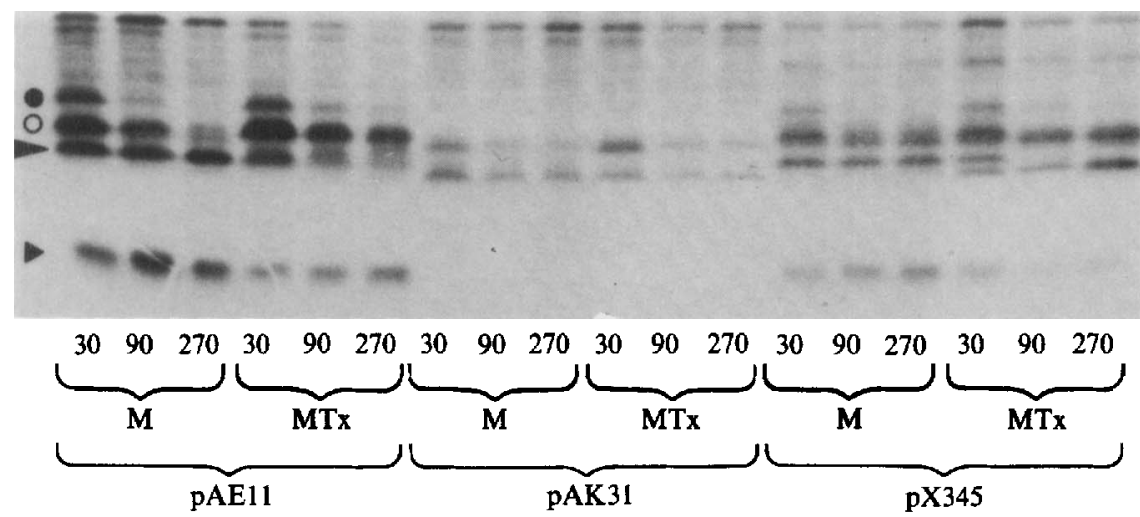

Fig. 7. Effect of Triton X-100 on Cal aceumulation in the cells of various strains. Cultures of $E$. coli W3110 containing various plasmids derived from pColA were treated with mitomycin $C$ in the absence (M) or presence of $0.1 \%$ Triton X-100 (MTx). They were labelled with [ ${ }^{35}$ S]methionine as indicated in Fig. 3. At various times after the chase (indicated in min on the figure), samples were centrifuged and the pellets mixed with loading buffer before being loaded onto the gel. Part of a fluorogram of the gel is presented. Migrations of the various forms of Cal are indicated as in Fig. 3.

aggregates and cannot be released to the medium despite the presence of a functional cal gene. These strains were induced with mitomycin $C$ in the presence of Triton X-100, labelled with $\left.{ }^{[35} S\right]$ methionine, and analysed after various times of chase on urea-SDS gels. Triton $X-100$ had no effect on strain W3110(pAK31), in which no functional Cal protein is present (Fig. 7). The same results were obtained with strain W3110(pJMM1) (data not shown). The effect of Triton $\mathrm{X}-100$ on strain W31 $10(\mathrm{pX} 345)$ was similar to that observed for the wild-type, resulting in a loss of Cal from the cells. Fig. 8 shows the effect of Triton X-100 on the culture supernatants of these various strains and on Citrobacter CA31 after $5 \mathrm{~h}$ of induction. The detergent enhanced the release of colicin $\mathrm{A}$ and of $\mathrm{Cal}$ in each $\mathrm{cal}^{+}$strain. In particular, release of colicin A-X345 was obtained under these conditions and became similar to the release of wild-type colicin A.

\section{DISCUSSION}

The experiments described in this paper show that the various functions of the Cal protein can be individually modified by various effectors. These functions are the release of colicin A, quasilysis, the activation of the outer membrane phospholipase $A$ and the killing of the producing cells.

Divalent cations abolished quasi-lysis and reduced killing but allowed a delayed release of colicin A for both wild-type and pld $A$ cells. EDTA, in contrast, caused a severe drop of $\mathrm{OD}_{600}$ and a high level of killing but weak release of colicin $A$ and a normal release of $C$ al in both types of cells. Triton X-100 increased the quasi-lysis, lethality and release of colicin, again with similar effects for pld $A^{+}$or pldA cells. It also caused a significant release of $\mathrm{Cal}$ to the culture supernatants.

Evidence that the colicin lysis proteins might exert their various functions by activating the outer membrane phospholipase A was first presented by Pugsley \& Schwartz (1984). This activation was proposed to trigger a cascade of events first involving an alteration of the membrane permeability due to the formation of lysophospholipids with detergent-like properties. This would result in the release of colicin and various other proteins, with quasi-lysis reflecting the leakage of these various cell components to the medium. It has been shown that mutants defective in phospholipase A do not undergo a pronounced quasi-lysis or release significant amounts of colicin E2 (Pugsley \& Schwartz, 1984), cloacin DF13 (Luirink et al., 1986) or colicin A (Cavard et al., 1987). The fact that these mutants could release colicin E2 (Pugsley \& Schwartz, 1984) in the presence of Triton X-100 has been explained as a bypass of the phospholipase $\mathrm{A}$ activation by the detergent. 


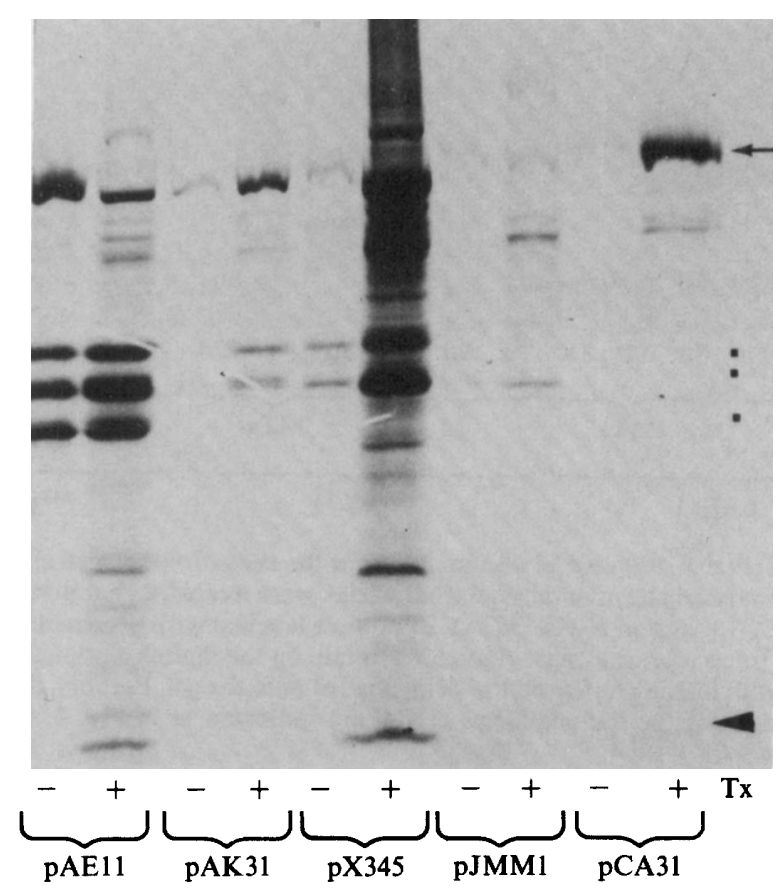

Fig. 8. Effect on Triton X-100 on Cal and colicin A release in various strains. Cultures of E. coli W3110 containing various plasmids as indicated on the figure were treated as described in Fig. 7 . After $5 \mathrm{~h}$ of induction, samples were centrifuged and the supernatants $(10 \mu l)$ were mixed with loading buffer and analysed on a gel. On the fluorogram presented, the positions of colicin $A(\rightarrow)$, fragments of colicin $A(\boldsymbol{\sigma})$ and mature $\mathrm{Cal}(\longrightarrow)$ are indicated.

Here we have shown that, in both $p l d A^{+}$and pldA cells, Triton X-100 causes the early release of not only colicin A but also the lysis protein, Cal, itself. This probably reflects the solubilization of the $\mathrm{Cal}$ protein from the envelope by the detergent. Fractionation of induced cells has indicated that Cal is localized mainly in the inner membrane of the cell (unpublished). Thus this result suggests that after a certain period of induction, the inner membrane becomes accessible to the detergent present in the medium whether or not the cells contain the PldA phospholipase. The detergent also results in quasi-lysis and the death of the cell without phospholipase activation, but all of these effects still depend on the presence of a functioning lysis protein, since none of them are observed in cells containing a mutant Cal (Fig. 7 and data not shown).

The effect of divalent cations in preventing quasi-lysis without markedly interfering with the release of colicin has been interpreted as reflecting either an interference with phospholipase A activation (Pugsley \& Schwartz, 1984) or an interference in an autolytic process which follows phospholipase A activation (Luirink et al., 1986). It has been shown that $\mathrm{Mg}^{2+}$ ions inhibit the autolysis of $E$. coli cells while EDTA provokes it (Leduc et al., 1982, 1984). However, experiments using autolytic-deficient mutants suggest that the autolytic system is not required for the function of the Cal protein and thus is not responsible for either the release of colicin A or quasi-lysis (Howard et al., 1987).

Furthermore, as for Triton X-100, the effects of varying the concentration of divalent cations were similar for both pldA $A^{+}$and pld $A$ cells. The addition of $\mathrm{Mg}^{2+}$ ions protected both W3110 and CBM cells from the lethal effects of induction, while EDTA increased these effects for both types of cells. Similarly, $\mathrm{Mg}^{2+}$ ions decreased the severity of quasi-lysis while EDTA increased it, again for both pld $A^{+}$and pldA cells, and for both strains the protection by $\mathrm{Mg}^{+2}$ was reversible, since the addition of EDTA caused an immediate loss of $\mathrm{OD}_{600}$. The effects of 
addition or removal of divalent cations on colicin release were more complex. For both pld $A^{+}$ and pldA cells the level of colicin release was reduced in the presence of EDTA, while it was slightly decreased in the presence of $\mathrm{Mg}^{2+}$. In fact, site-directed mutagenesis studies suggest that a positive charge of $\mathrm{Cal}$ protein may be important for its function (Howard et al., 1989). Therefore, Cal may disturb the membrane surface potential in such a way that addition of divalent cations could attenuate the resulting cytolysis and maintain the envelope structure.

The effects of the various agents tested on the functions of Cal suggest that it causes extensive damage to the $E$. coli cell envelope irrespective of the presence of phospholipase in the outer membrane of the producing cells. Although pldA cells are less likely to die, release less colicin and display less quasi-lysis than wild-type cells, all of these effects are still pronounced during colicin induction. We propose that the presence of the Cal lipoprotein accumulating throughout induction disorganizes the structure of the envelope of the cells. Thus the outer membrane becomes permeable and sensitive to the action of detergents and control over the activity of the phospholipase is lost. Further damage is caused by the activity of this enzyme or by added detergent, resulting in the actual loss of membrane material (including Cal) by solubilization or blebbing, as previously described for membrane structure mutants (Chakraborti et al., 1986). Divalent cations would presumably protect the envelope against these events by forming salt bridges between the negatively charged phospholipid and LPS constituents of the envelope.

Further experiments are required in order to determine both the molecular nature of the changes in the envelope caused by $\mathrm{Cal}$ and the mechanism by which they are brought about.

We thank M. Payan for careful preparation of the manuscript. This work was supported by the 'Centre National de la Recherche Scientifique' and the 'Fondation pour la Recherche Médicale'. S. P. Howard was the recipient of a Natural Sciences and Engineering Research Council of Canada post-doctoral fellowship.

\section{REFERENCES}

Altieri, M., Suit, J. L., FAN, M. L. J. \& Luria, S. E. (1986). Expression of the cloned ColE1 kil gene in normal and $\mathrm{kil}^{\mathrm{R}}$ Escherichia coli. Journal of Bacteriology 168, 648-654.

AMEs, G. F. (1968). Lipids of Salmonella typhimurium and Escherichia coli: structure and metabolism. Journal of Bacteriology 95, 833-843.

Baty, D., Knibiehler, M., VerheiJ, H., Pattus, F., Shire, D., Bernadac, A. \& Lazdunski, C. (1987a). Site-directed mutagenesis of the COOH-terminal region of colicin $\mathrm{A}$ : effect on secretion and voltagedependent channel activity. Proceedings of the National Academy of Sciences of the United States of America 84, 1152-1156.

Baty, D., Lloubés, R. Geli, V., Lazdunski, C. \& Howard, S. P. $(1987 b)$. Extracellular release of colicin A is non-specific. EMBO Journal 6, 24632468.

Cavard, D., Lloubés, R., Morlon, J., Chartier, M. \& LAZDUNSKI, C. (1985). Lysis protein encoded by plasmid ColA-CA31. Gene sequence and export. Molecular and General Genetics 199, 95-100.

Cavard, D., Crozel, V., Gorvel, J. P., Pattus, F., BATY, D. \& LAZDUNSKI, C. (1986). A molecular, genetic and immunological approach to the functioning of colicin A, a pore-forming protein. Journal of Molecular Biology 187, 449-459.

Cavard, D., Baty, D., Howard, S. P., VerheiJ, H. M. \& LAZDUNSKI, C. (1987). Lipoprotein nature of the colicin A lysis protein: effect of amino acid substitutions at the site of modification and processing. Journal of Bacteriology 169, 2187-2194.
Chakraborti, A. S., Ishidate, K., Cook, W. R., ZRIKe, J. \& RothFIELD, L. J. (1986). Accumulation of a murein-membrane attachment site fraction when cell division is blocked in $l k y D$ and cha mutants of Salmonella typhimurium and Escherichia coli. Journal of Bacteriology 168, 1422-1429.

De GraAF, F. K. \& OUdeGA, B. (1986). Production and release of cloacin DF13 and related colicins. Current Topics in Microbiology and Immunology 125, 183205.

Howard, S. P., Leduc, M., Van Heijenoort, J. \& LAZDUNSKI, C. (1987). Lysis and release of colicin A in colicinogenic autolytic deficient Escherichia coli mutants. FEMS Microbiology Letters 42, 147-151.

Howard, S. P., Cavard, D. and Lazdunski, C. (1989). Amino acid sequence and length requirements for assembly and function of the colicin A lysis protein. Journal of Bacteriology 171, 410-418.

JAMES, R., JARVIS, M. \& BARKER, D. F. (1987). Nucleotide sequence of the immunity and lysis region of the ColE9-J plasmid. Journal of General Microbiology 133, 1553-1562.

Leduc, M., KasRa, R. \& VAN Heijenoort, J. (1982). Induction and control of the autolytic system of Escherichia coli. Journal of Bacteriology 152, 26-34. Leduc, M., KasRa, R., Singer, H. \& VAN HeijnoORT, J. (1984). EDTA induced autolysis in Escherichia coli and isolation of resistant mutants. FEMS Microbiology Letters 23, 137-142.

Lloubés, R., Baty, D. \& LAzdunski, C. (1986). The promoters of the genes for colicin production, release and immunity in the ColA plasmid: effects of 
convergent transcription and LexA protein. Nucleic Acids Research 14, 2621-2636.

Luirink, J., Van DeR SANDE, C., Tommassen, J., VeltKamp, E., De Graaf, F. K. \& Oudega, B. (1986). Effects of divalent cations and of phospholipase A activity on excretion of cloacin DF13 and lysis of host cells. Journal of General Microbiology 132, 825-834.

LuirinK, J., De GraAF, F. K. \& OUdega, B. (1987). Uncoupling of synthesis and release of cloacin DF13 and its immunity protein by Escherichia coli. Molecular and General Genetics 206, 126-132.
Pugsley, A. P. (1988). The immunity and lysis genes of ColN plasmid pCHAP4. Molecular and General Genetics 211, 335-341.

Pugsley, A. P. \& Schwartz, M. (1983). A genetic approach to the study of mitomycin-induced lysis of Escherichia coli K12 strains which produce colicin E2. Molecular and General Genetics 190, 266-372.

Pugsley, A. P. \& Schwartz, M. (1984). Colicin E2 release: lysis, leakage or secretion? Possible role of a phospholipase. EMBO Journal 3, 2393-2397. 